\title{
Induction of protective immunity to Theileria annulata using two major merozoite surface antigens presented by different delivery systems
}

\author{
Christine d'Oliveira*, Andries Feenstra*, Helma Vos $\dagger$, \\ Albert D.M.E. Osterhaus $\dagger$, Brian R. Shiels $\ddagger$, Albert W.C.A. Cornelissen* \\ and Frans Jongejan* $\S$
}

Allelic forms (Tams1-1 and Tams1-2) of the major merozoite surface antigen gene of Theileria annulata have recently been expressed in Escherichia coli and in Salmonella typhimurium aroA vaccine strain SL3261. To test the potential of subunit vaccines against $\mathrm{T}$. annulata infection, we immunized four groups of three calves with either recombinant (re-) (Tams1-1 and Tams1-2) proteins or naked DNA encoding these antigens. Group I was immunized intramuscularly with both re-proteins incorporated into immunostimulating complexes (ISCOMs). Group II was inoculated intramuscularly with naked plasmid DNA encoding Tams1-1 and Tams1-2. Groups III and IV received S. typhimurium SL3261 [pSTams1-1][pIP5] and SL3261[pSTams1-2][pIP5] subcutaneously and orally, respectively. A final group of three animals (Group V) served as an unimmunized control group. Four weeks after the last immunization all calves were challenged with a $\mathrm{T}$. annulata stabilate generated from blood of an infected animal with $30 \%$ piroplasm parasitaemia. All calves vaccinated with ISCOMs proved to be protected from $\mathrm{T}$. annulata infection and had generated antibodies against both re-(Tams1-1 and Tams1-2) at the time of challenge. In two of these animals the antibody had a surface binding profile by IFAT. Two of three calves immunized with naked DNA also proved to be protected, but none of the animals had generated any detectable antibodies against the recombinants. Salmonella-based delivery of the recombinants did not induce any protection; two of six animals died of theileriosis and there was no difference between subcutaneous or oral administration. These preliminary results show that re-(Tams1-1 and/or Tams1-2) may elicit protective immune responses in cattle, depending on the antigen delivery system. (C) 1997 Elsevier Science Ltd.

Keywords: ISCOMs; naked DNA; Salmonella; protection; Theileria annulata; cattle

The protozoan parasite Theileria annulata infects cattle and domestic buffalo (Bubalus bubalis) across an area stretching from southern Europe and northern Africa, through the Middle East and southern Russia into India and southern China'. T. annulata is transmitted by ticks of the genus Hyalomma and more than 250

\footnotetext{
*Department of Parasitology and Tropical Veterinary Medicine, Faculty of Veterinary Medicine, Utrecht University, Utrecht, Netherlands. HInstitute of Virology, Erasmus University Rotterdam, Rotterdam, Netherlands. \$Department of Veterinary Parasitology, University of Glasgow, Glasgo, UK §To whom correspondence should be addressed. Utrecht University, P.O. Box 80165, 3508 TD Utrecht, Netherlands. Tel.: (31-30) 2532568; fax: (31-30) 2540784; e-mail: f.jongejan@vetmic.dgk.ruu.nl. (Received 24 October 1996; revised version received 3 March 1997; accepted 26 March 1997)
}

million domestic cattle have been estimated to be at risk from tropical theileriosis ${ }^{2}$. Infection in the bovine is initiated by inoculation of sporozoites from infected ticks during feeding. These invade mononuclear leucocytes (thought primarily to be monocytes and B-cells expressing MHC class II antigens ${ }^{3.4}$, where they develop into multinucleated macroschizonts and induce host cells to divide in synchrony with the macroschizont. These parasites develop further from microschizonts into free merozoites, which upon release from the leucocyte invade erythrocytes to develop into piroplasms.

Tropical theileriosis is currently controlled by chemotherapy, tick control using acaricides and vaccination using attenuated macroschizont-infected lymphoid cell lines. Although these live vaccines are being used with success in endemic areas ${ }^{5-10}$, their 
application has a number of drawbacks. The vaccine lines need to be evaluated for their ability to protect against challenge, require prolonged in vitro passage to become attenuated and it is not clear whether attenuated cells can revert to virulence in vivo. Such prolonged passage can also lead to lines losing their ability to immunize recipient animals as a result of the inability of the macroschizonts to transfer into the cells of the vaccinated animal. Furthermore, although cattle are protected by the attenuated cell line vaccine, it does not prevent the development of the erythrocytic stages when animals are challenged"I. In addition, once thawed the vaccine has a short half life and there is the possibility of transferring other pathogens by the use of such live vaccines. Many of these limitations could be overcome by the production of immunogenic antigens by re-DNA techniques and development of a subunit vaccine against tropical theileriosis.

One antigen (SPAG-1) has been identified on the surface of the sporozoite by a mAb which blocks sporozoite penetration of bovine peripheral blood mononuclear cells in vitro ${ }^{12}$. A C-terminal fragment (SR1) of SPAG-1 has been expressed as a fusion protein in the el loop of hepatitis $B$ core antigen $(\mathrm{HBcAg})$ and used to immunize calves in a small scale vaccination trial. High antibody titres were generated in all four animals immunized with $\mathrm{HBcAg-SR} 1$ and IFAT confirmed that there was recognition of the sporozoite surface. Clinical symptoms were delayed on sporozoite challenge; however, all the animals eventually developed disease ${ }^{13}$.

The merozoite stage is, like the sporozoite, invasive and also a potential target for a protective immune response. Recently, allelic forms of Tams1 (Tams1-1 and Tams1-2) which encode the $30 \mathrm{kDa}$ and $32 \mathrm{kDa}$ major merozoite surface antigens of $T$. annulata. respectively, have been expressed in a Salmonella typhimurium aro $A$ vaccine strain and Escherichia coli ${ }^{14}$ Immunostimulating complexes (ISCOMs) were prepared from both recombinants purified from $E$. coli. As a third route to deliver re-(Tams1-1 and Tams 1-2) to the bovine host, both genes were subcloned into an eukaryotic expression vector and used as a DNA vaccine. In this paper we evaluate the potential of these three systems as a component of a multistage subunit vaccine against tropical theileriosis in cattle.

\section{MATERIALS AND METHODS}

\section{Bacterial strains and culture}

Escherichia coli M15[pREP4] ${ }^{15}$ and Salmonella typhimurium SL3261 ${ }^{16}$ producing re-(Tams1-1 or Tams1-2) were grown as described previously ${ }^{14}$. S. typhimurium SL3261 [pSTams1-1][pIP5] and SL3261[pSTams12][pIP5] used for animal experiments were washed in PBS and each was resuspended at $1 \times 10^{9} \mathrm{ml}^{-1}$ and $2 \times 10^{111} \mathrm{ml}^{-1}$ for subcutaneous and oral administration, respectively. The hacteria were checked for the correct aro, his, $\mathrm{Ap}^{\mathrm{R}}$ and $\mathrm{Km}^{\mathrm{R}}$ phenotypes by selection on appropriate minimal plates ${ }^{17}$ with or without $10 \mu \mathrm{g} \mathrm{ml} l^{-1}$ para-aminobenzoic acid, $10 \mu \mathrm{g} \mathrm{ml}^{-1}$ 2,3-dihydroxybenzoic acid, $40 \mu \mathrm{g} \mathrm{ml}^{-1}$ phenylalanine, $40 \mu \mathrm{g} \mathrm{ml}^{-1}$ tyrosine, $40 \mu \mathrm{g} \mathrm{ml}^{-1}$ histidine, $40 \mu \mathrm{g} \mathrm{ml}^{-1}$ tryptophan, and by culture on LB plates supplemented with $100 \mu \mathrm{g} \mathrm{ml}^{-1}$ ampicillin (Ap) and $25 \mu \mathrm{g} \mathrm{ml}^{-1}$ kanamycin
$(\mathrm{Km})$. To distinguish $S$. typhimurium from $E$. coli, growth was tested on brilliant green agar (BGA) plates. Smooth LPS phenotype was determined by examining LPS profiles on silver-stained gels ${ }^{18}$. Briefly, whole cell lysates were boiled for $10 \mathrm{~min}$, incubated with $125 \mu \mathrm{g}$ proteinase $\mathrm{K}$ at $60^{\circ} \mathrm{C}$ for $1 \mathrm{~h}$ and subsequently examined by sodium dodecyl sulphate polyacrylamide gel electrophoresis (SDS-PAGE) followed by silver staining. S. typhimurium-Smooth and -Rough (ATCC 14028), kindly provided by Dr J.G. Kusters, and $E$. coli were used as controls.

\section{Preparation of ISCOMs containing re-(Tams1-1 or Tams1-2)}

Production and isolation from $E$. coli M15[pETams1-1+][pREP4] and M15[pETams1$2+][$ pREP4] of re-(Tams1-1 and Tams1-2), respectively, were performed as described previously ${ }^{14}$. For the preparation of ISCOMs, recombinants were mixed separately with cholesterol, phosphatidylcholine (Sigma Chemical Co., St. Louis, MO, USA) and Quil A (Spikoside, Iscotec, Lulea, Sweden) at a ratio of 1:1:5 (w/w/w). After ultrasonic treatment for $10 \mathrm{~min}$ the mixture was incubated for $1 \mathrm{~h}$ at room temperature. Subsequently, the mixture was extensively dialysed against $10 \mathrm{mM}$ Tris- $\mathrm{HCl}(\mathrm{pH} 7.4), 0.3 \mathrm{M} \mathrm{NaCl}$, layered over a linear $(10-60 \%)$ sucrose gradient and centrifuged for $18 \mathrm{~h}$ at $25 \mathrm{~K}$ (Beckmann SW28 rotor). Fractions containing peak levels of the recombinants (coinciding with the presence of ISCOM-like structures, as judged by negative contrast electron microscopy) were pooled. For SDS-PAGE and subsequent Western blotting, ISCOMs were pelleted by ultracentrifugation for $4 \mathrm{~h}$ at $40 \mathrm{~K}$ and resuspended in PBS $(1 / 10$ of the initial volume).

\section{Cloning of Tams $1-1$ and Tams $1-2$ in pSLRSV.Nul}

Primers for PCR were chosen which were complementary to conserved sequences flanking Tams $1-1$ and Tams 1-2. Primer 1: 5'-GGAATTAGATCTATGTTGTCCAGGACCACC-3' and primer 2: 5'-AATTCCAGATCTGGGTTTTAAAGGAAGTAAAGG-3'. $\quad B g l$ II restriction sites (presented in bold) were incorporated to facilitate subsequent cloning. The positions of the start and stop codons are underlined in primer 1 and primer 2, respectively. PCR was performed in a final reaction volume of $100 \mu \mathrm{l}$ containing $50 \mathrm{mM} \mathrm{KCl}$, $10 \mathrm{mM}$ Tris- $\mathrm{HCl}(\mathrm{pH} 8.3), 0.1 \%$ Triton X-100, $1.5 \mathrm{mM}$ $\mathrm{MgCl}_{2}, 200 \mu \mathrm{M}$ (each) deoxynucleoside triphosphate, $80 \mathrm{pmol}$ of each primer, $2.5 \mathrm{U}$ Taq polymerase (Promega, Madison, WI, USA) and $10 \mathrm{ng}$ of plasmid DNA containing Tams 1-1 or Tams 1-2. Reactions were performed in an automatic DNA thermal cycler (Perkin-Elmer, Foster City, CA, USA) for 30 cycles comprising denaturation at $94^{\circ} \mathrm{C}$ for $1 \mathrm{~min}$, annealing at $55^{\circ} \mathrm{C}$ for $1 \mathrm{~min}$ and extension at $72^{\circ} \mathrm{C}$ for $1 \mathrm{~min}$. The resulting 851 -bp fragments were separated by electrophoresis on a $1.2 \%$ low-melting point agarose gel and isolated using QiaexII (Qiagen, Chatsworth, CA, USA). These fragments containing the complete coding sequence of Tams $1-1$ and Tams $1-2$, were ligated into expression vector pSLRSV.Nul, digested with $B g l I I$ and treated with Calf-Intestinal-Phosphatase ${ }^{17}$. Plasmid pSLRSV.Nul/BglII-version was kindly provided by Prof. L. Babiuk and modified by $\mathrm{Dr}$ J. 
Lewis (personal communication) ${ }^{19-21}$. The resulting plasmids pBglII30 and pBglII32 contained the $30 \mathrm{kDa}$ and $32 \mathrm{kDa}$ merozoite surface antigen coding sequences, respectively, both under control of the Rous Sarcoma Virus-Long Terminal Repeat promoter and the SV-40 polyadenylation signal. The plasmid backbone was derived from pSL301 ${ }^{\mathrm{TM}}$ (Invitrogen, San Diego, CA, USA). Both plasmids were purified from $E$. coli DH5 $\alpha$ using Qiagen columns (Qiagen) and verified by nucleotide sequence analysis ${ }^{22}$.

\section{Immunizations}

Experimental calves (Bos taurus), 5-6 months of age and kept in experimental tick-proof pens were used in the experiments. Fifteen calves were allocated randomly into five groups of three animals each and immunized according to the schedule summarized in Table 1. Each immunization consisted of two preparations: one contained re-(Tams1-1), given on the righthand side in the neck of the animal, and the other contained re-(Tams1-2), given on the left-hand side in the neck.

(1) Group I: $1 \mathrm{ml}$ ISCOM vaccine given intramuscularly, containing $20 \mu \mathrm{g}$ re-(Tams $1-1$ or Tams1-2);

(2) Group II: $1 \mathrm{ml}$ DNA vaccine given intramuscularly, containing $500 \mu \mathrm{g}$ of pBglII30 or pBglII32 dissolved in TE $[10 \mathrm{mM}$ Tris- $\mathrm{HCl}(\mathrm{pH} 8), 1 \mathrm{mM}$ EDTA];

(3) Group III: $1 \mathrm{ml}$ Salmonella vaccine given subcutaneously, containing $1 \times 10^{9} \quad \mathrm{~S}$. typhimurium SL3261[pSTams1-1][pIP5] or SL3261[pSTams1. 2||$p I P 5 \mid$ :

(4) Group IV: $5 \mathrm{ml}$ Salmonella vaccine given orally, containing $1 \times 10^{11}$ S. typhimurium SL3261[pSTams1-1][pIP5] or SL3261[pSTams 1-2][pIP5];

(5) Group V: three unimmunized control calves were infected with $T$. annulata only.

Rectal temperatures were taken daily and blood was collected weekly for sera analysis. Additional blood samples were collected three times weekly in citrate buffer for the preparation of blood smears and determination of packed cell volume (PCV). The remainder of the blood sample was stored at $-20^{\circ} \mathrm{C}$ for PCR analysis. T. annulata piroplasms were counted in Giemsa-stained blood smears. When very scanty, their presence was confirmed by PCR and subsequently Southern hybridization using Tams $1-1 \operatorname{cDNA}^{23}$ as a probe, as described previously ${ }^{24}$. Blood samples for PCR were collected from Groups I and II prior to challenge and in weeks $2,3,4,8$ and 12 postchallenge. Saponin lysis mix $(0.22 \% \mathrm{NaCl}, 0.015 \%$ saponin, $1 \mathrm{mM}$ EDTA) was added to $50 \mu \mathrm{l}$ of blood and the mixture was centrifuged for $1 \mathrm{~min}$. Pellets were washed three times with saponin lysis mix, resuspended in $100 \mu \mathrm{l}$ PCR buffer $(50 \mathrm{mM} \mathrm{KCl}, 10 \mathrm{mM}$ Tris-I ICl (plI 8), $0.5 \%$ Tween $20,100 \mu \mathrm{g}$ proteinase $\mathrm{K} \mathrm{ml} \mathrm{ml}^{-1}$ ) and incubated at $56^{\circ} \mathrm{C}$ for $1 \mathrm{~h}$. After $10 \mathrm{~min}$ at $95^{\circ} \mathrm{C}$, $5 \mu \mathrm{l}$ were used for PCR, performed as described above.

\section{Challenge}

Calf 184 was experimentally infected with $T$. annulata (Ankara, Turkey) ( $^{25}$ administered as a ground-up tick supernate, kindly provided by Prof. C.G.D. Brown. When the parasitaemia (piroplasms) reached $30 \%$, blood was frozen with $10 \%$ DMSO in $2 \mathrm{ml}$ aliquots at $-80^{\circ} \mathrm{C}$, representing approximately $6 \times 10^{9}$ piroplasms per aliquot, plus an unknown number of macroschizont-infected leucocytes. Control and immunized animals were challenged with this stabilate administered subcutaneously $(1 \mathrm{ml})$ and intravenously $(1 \mathrm{ml})$ in the neck of the animal (Table 1 ).

\section{Western blotting}

Column-purified re-(Tams1-1 and Tams1-2) and proteinase K-digested whole cell lysates of $S$. typhimurium SL3261 were separated by $0.1 \%$ SDS-12\% PAGE $^{17}$. Purified S. typhimurium LPS (Sigma) was used as a control. Subsequently, Western blot analysis was performed using preimmune, prechallenge and postchallenge sera from immunized calves at a 1:100 dilution and, as a control, rabbit anti-LPS serum, kindly provided by Edwin J. Tijhaar. Pelleted ISCOMs werc scparatcd and the Western blot analysed as described above, using immune serum from calf 184. $\mathrm{Ab}-\mathrm{Ag}$ complexes were visualized using FCL immunodetection (Amersham, Buckinghamshire, UK).

\section{Indirect immunofluorescent antibody assay}

T. annulata (Ankara, Turkey) ${ }^{25}$ piroplasm infected erythrocytes were prepared by centrifugation of blood at $800 \mathrm{~g}$ for $10 \mathrm{~min}$. Pelleted cells were washed twice in PBS, resuspended to a density of approximately $3 \times 10^{7} \mathrm{ml}^{-1}$ and fixed in acetone at $-20^{\circ} \mathrm{C}$ for $20 \mathrm{~min}$. The indirect antibody test was carried out essentially as described by Minami et $a l^{26}$. Briefly, sera isolated at the lime of challenge from ISCOM immunized animals (Group I) and control calf 476 (Group V) and at weeks 2, 3 and 9 postchallenge were assayed by incubating $20 \mu$ of a 1:50 dilution (in PBS/20\% horse serum) on each well at room temperature for $30 \mathrm{~min}$, followed by washing three times with PBS. Fluorescein-conjugated rabbit anti-bovine $\lg G$ (Sigma) was added to each well and incubated for a further $30 \mathrm{~min}$ at room tempera-

Table 1 Vaccination schedule for four groups of three calves each immunized with re-(Tams1-1 and Tams1-2) either prepared as ISCOMs, encoded on plasmid pBglil30 and pBglil32, respectively, or produced in S. typhimurium vaccine strain SL3261

\begin{tabular}{|c|c|c|c|c|c|c|c|c|}
\hline \multirow{2}{*}{$\begin{array}{l}\text { Animal } \\
\text { group }\end{array}$} & \multirow[b]{2}{*}{ Delivery system } & \multirow[b]{2}{*}{ Route } & \multicolumn{6}{|c|}{ Week $^{a}$} \\
\hline & & & 0 & 1 & 4 & 5 & 8 & 12 \\
\hline ॥ & pBgilli30 and -32 & Intramuscular & + & - & + & - & + & $\mathrm{C}$ \\
\hline III & Salmonella SL3261 & Subcutaneous & + & + & - & $\mathrm{C}$ & & \\
\hline IV & Salmonella SL3261 & Oral & + & + & - & $\mathrm{C}$ & & \\
\hline V & Unimmunized control & Intravenous and subcutaneous & - & - & - & - & C & \\
\hline
\end{tabular}

${ }^{a} \mathrm{C}$, challenged with $T$. annulata 
ture. After washing as above, slides were stained with $0.1 \%$ Evans blue, mounted with $50 \%$ glycerol in PBS and examined by microscopy under UV illumination at $\times 500$ magnification $^{27}$.

\section{RESULTS}

\section{ISCOM immunized calves}

The characteristic cage-like structure of the ISCOMs was confirmed by electron microscopy after negative staining (data not shown). After performing SDS-PAGE of the pelleted ISCOMs, Western blot analysis using $T$. annulata immune calf serum revealed bands at approximately $32 \mathrm{kDa}$ and $33 \mathrm{kDa}$ (Figure $1(\mathrm{~A})$, lanes 1 and 2$)$, confirming the presence of purified re-(Tams1-1) and re-(Tams1-2), respectively (Figure 1(A), lanes 3 and 4).

Group I calves were immunized twice with ISCOMs intramuscularly, with an interval of 4 weeks (Table $l$ ) and proved to he protected against $T$. annulata challenge (Table 2). Western blot analysis revealed that all three animals had gcncratcd antibodics against
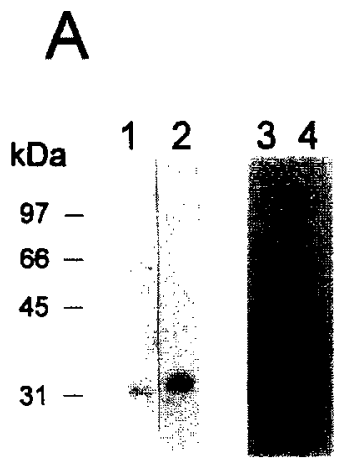
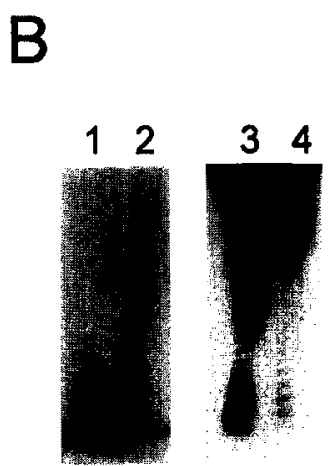

Figure 1 (A) Western blot analysis of re-(Tams1-1 and Tams1-2) ISCOMs (lanes 1 and 2, respectively) using $T$. annulata immune serum, and Coomassie brilliant blue-stained re-Tams1-1 and re-Tams 1-2 proteins run in parallel (lanes 3 and 4, respectively). (B) SDS-PAGE of S. typhimurium LPS stained with silver (lanes 1 and 2) and Western blot analysed using rabbit anti-LPS serum (lanes 3 and 4). Lanes: 1, S. typhimurium SL3261; 3, purified S. typhimurium LPS (Sigma)
re-(Tams1-1 and Tams1-2) at the time of challenge [Figure 2(A), lanes 1, 2, 5, 6, 9 and 10]. Although there were equal amounts of recombinant proteins loaded onto the gel [Figure 1(A), lanes 3 and 4 ], the sera preferentially detected re-(Tams1-2) [Figure 2(A), lanes 2,6 and 10], indicating that it was more immunogenic than the ISCOMs prepared from re-(Tams1-1) [Figure 2(A), lanes 1, 5 and 9]. Specific antibody levels were maintained in the sera of all three animals at least until week 23 postchallenge when the experiment was terminated [Figure 2(A), lanes 3, 4, 7, 8, 11 and 12], whercas the levels in control calf 476 (Group V) were almost non-detectable [Figure 2(A), lanes 15 and 16]. Furthermore, sera taken at the time of challenge from calves 473 and 474 reacted with piroplasm antigen in IFAT, whereas serum from calf 475 showed a weak recognition (Figure 3). Sera taken from the three immunized and one control animal at week 9 postchallenge recognized the piroplasms and preimmune sera did not react with either the recombinants or piroplasms (data not shown).

The protected animals (Nos. 473, 474 and 475) were confirmed to be $T$. annulata carriers by PCR (Figure 4 and Southern hybridization [Figure $4(\mathrm{~B})]$. The expected 778-bp fragment was amplified in all three animals at week 12 postchallenge [Figure $4(\mathrm{~B})$, lanes 9 (after longer exposure), 15 and 22]. Calf 475, which developed a maximum piroplasm parasitaemia of $1 \%$ was already positive by PCR at week 3 postchallenge (Figure 4, lane 19) and showed a profile similar to control calf 476 (Figure 4, lanes 23-28). Calf 474 developed a $25 \%$ piroplasm parasitaemia in week 23 postchallenge (Figure 4, lane 16) and was treated with Butalex $^{\mathrm{TM}}$ (Mallinckrodt Veterinary, Uxbridge, UK) at a dose rate of $2.5 \mathrm{mg} \mathrm{kg}$ ' body weight.

\section{Naked DNA immunized calves}

Group II was immunized three times intramuscularly at 4 -week intervals using $500 \mu \mathrm{g}$ pBglII30 and $500 \mu \mathrm{g}$ pBgll132 in each immunization (Table 1). SDS-PAGE and Western blot analysis with sera collected just before every boost or challenge did not reveal any detectable antibodies against the recombinants. Sera used at a 1:10 dilution instead of 1:100 was also

Table 2 Induction of protective immunity to $T$. annulata in different groups of calves immunized with re-(Tams1-1 and Tams1-2) either prepared as ISCOMs, encoded on plasmid pBglll30 and pBglli32, or produced in S. typhimurium vaccine strain SL3261

\begin{tabular}{|c|c|c|c|c|c|c|}
\hline \multirow[b]{2}{*}{ Group no. } & \multirow[b]{2}{*}{ Calf no. } & \multirow[b]{2}{*}{ Delivery system } & \multicolumn{3}{|c|}{ Maximum values } & \multirow[b]{2}{*}{ Final outcome } \\
\hline & & & Temperature $\left({ }^{\circ} \mathrm{C}\right)$ & Parasitaemia (\%) & PCV reduction (\%) & \\
\hline \multirow[t]{3}{*}{ 1 } & 473 & \multirow[t]{3}{*}{ ISCOMs } & 39.2 & $<0.1$ & 14 & Protected \\
\hline & 474 & & 39.1 & $<0.1$ & 18 & Protected $^{a}$ \\
\hline & 475 & & 39.2 & 1 & 19 & Protected \\
\hline \multirow[t]{3}{*}{ ॥ } & 519 & \multirow[t]{3}{*}{ Plasmid DNA } & 41.6 & 35 & 52 & Theileriosis $^{b}$ \\
\hline & 520 & & 40.8 & 1 & 18 & Protected \\
\hline & 521 & & 39.0 & 0.1 & 14 & Protected \\
\hline \multirow[t]{3}{*}{ III } & 3033 & \multirow[t]{3}{*}{ Salmonella s.c. } & 41.0 & 8 & 56 & Theileriosis $^{b}$ \\
\hline & 7643 & & 41.5 & 8 & 49 & Theileriosis $^{b}$ \\
\hline & 9263 & & 41.9 & 50 & 78 & Fatal theileriosis \\
\hline \multirow[t]{3}{*}{ IV } & 7775 & \multirow[t]{3}{*}{ Salmonella oral } & 41.2 & 3 & 44 & Theileriosis $^{b}$ \\
\hline & 1045 & & 41.9 & 50 & 68 & Fatal theileriosis \\
\hline & 4063 & & 41.9 & 3 & 58 & Theileriosis $^{b}$ \\
\hline \multirow[t]{2}{*}{ V } & 397 & \multirow[t]{2}{*}{ None } & 41.7 & 20 & 66 & Theileriosis \\
\hline & 403 & & 41.8 & 18 & 57 & Theileriosis $^{\circ}$ \\
\hline
\end{tabular}

${ }^{a}$ Animal developed tropical theileriosis at week 23 postchallenge, and was treated with Butalex ${ }^{\mathrm{TM}}$, dose rate $2.5 \mathrm{mg}$ ml body weight

${ }^{\circ}$ Animal recovered without treatment 
negative (data not shown). However, calves 520 and 521 were protected, whereas calf 519 was not (Table 2). PCR analysis confirmed that all animals were carriers of T. annulata (data not shown).

\section{Recombinant Salmonella immunized calves}

SL3261[pSTam1-1 or pSTams1-2]lpIP5] showed the characteristic pattern of smooth LPS after SDS-PAGE required by Salmonella for infecting host macrophages (data not shown). The aroA and his deletions of SL3261[pSTams1-1 or pSTams1-2][pIP5], required for the avirulent Salmonella to be useful as vaccine, were confirmed by growth limited to minimal plates supplemented with both the aromatic compounds and histidine. Growth of transformed SL3261 on LB containing both $A p$ and $\mathrm{Km}$ confirmed the presence of both pSTams1-1 or pSTams1-2 and pIP5. As an additional control, $S$. typhimurium and $E$. coli could be distinguished on BGA plates.
Groups III and IV were immunized twice subcutaneously and orally, respectively, with Salmonella producing re-(Tams1-1 and Tams1-2) (Table 1). All animals developed fever accompanied by piroplasm parasitaemia. Calves 9263 (Group III) and 1045 (Group IV) died of acute theileriosis. The other two animals from Group III developed a parasitaemia of $8 \%$, whereas the two remaining animals from Group IV exhibited a maximum parasitaemia of $3 \%$. Western blot analysis showed that all immunized animals had been infected with Salmonella at the time of challenge (Figures 2(B) and 2(C)). Sera from calves 9263 and 1045 (both died subsequently) contained fewer antibodies against Salmonella LPS [Figure 2(B), lanes 11 and 12, Figure 2(C), lanes 7 and 8, respectively] in comparison with sera from animals that survived challenge [Figure 2(B), lanes 3, 4, 7 and 8, Figure 2(C), lanes $3,4,11$ and 12]. Furthermore, only calves 3033 and 9263 , both immunized subcutaneously, had generated antibodies against re-Tams1-1 and to a lesser
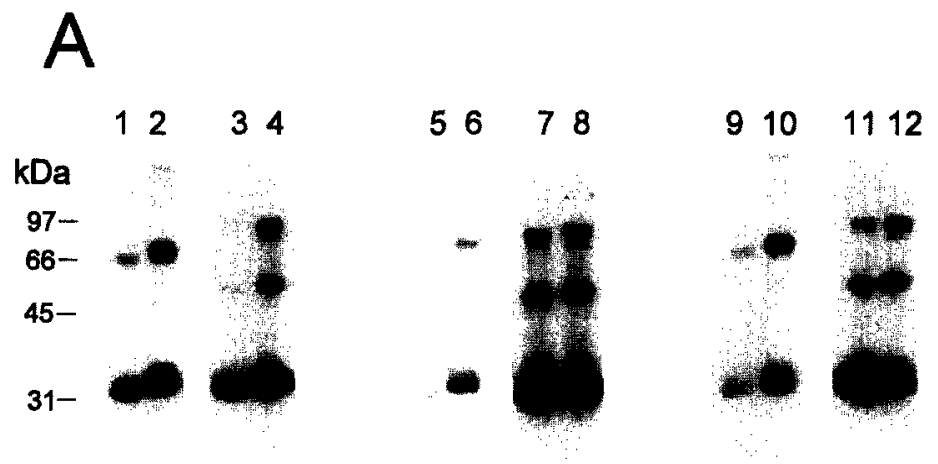

\section{6}
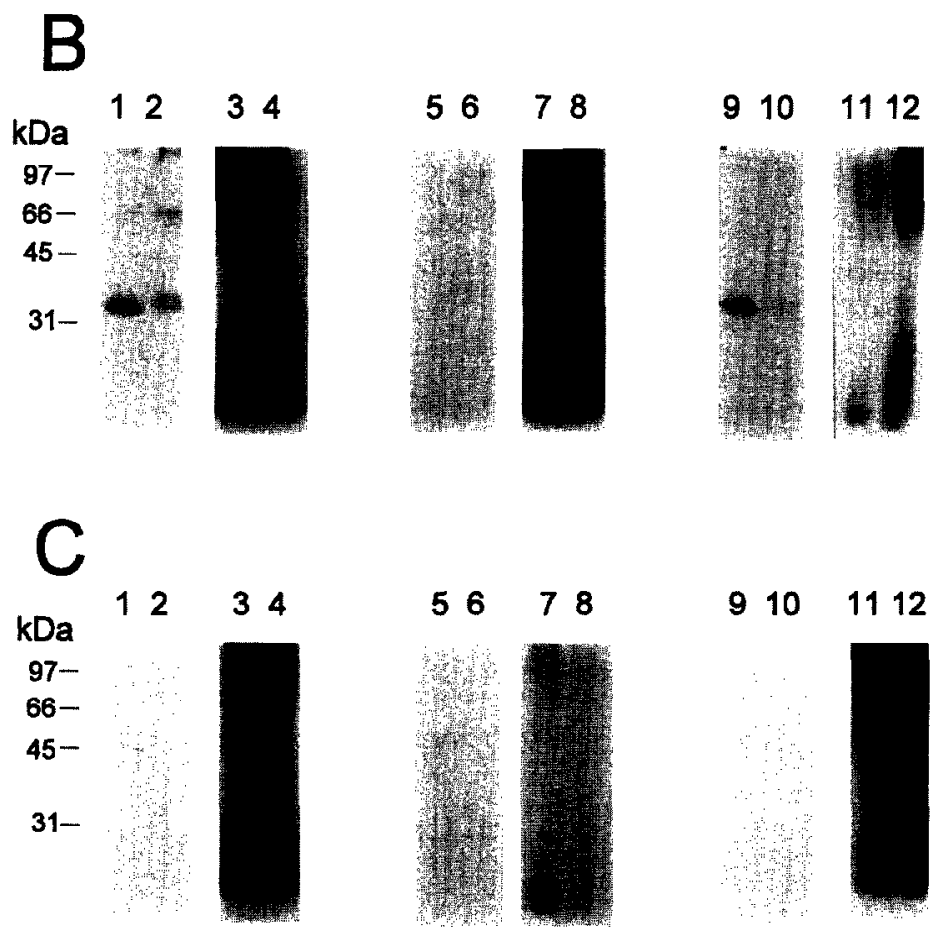

Figure 2 (A) Western blot analysis of re-Tams1-1 and re-Tams1-2, respectively, using sera from ISCOM immunized calves (Group I) and control animal 476 (Group V). Lanes 1 and 2, serum from calf 473 at the time of challenge (t.c); lanes 3 and 4 , week 23 postchallenge (p.c); lanes 5 and 6 , calf 474 t.c; lanes 7 and 8 , week 23 p.c; lanes 9 and 10, calf 475 t.c; lanes 11 and 12 , week 23 p.c; lanes 13 and 14 , calf 476 preimmune serum; lanes 15 and 16, week 23 p.c. (B) Western blot analysis of re-(Tams1-1 and Tams 1-2) (lanes 1, 2, 5, 6, 9 and 10) and S. typhimurium LPS (lanes 3, 4, 7, 8, 11 and 12) using sera from recombinant Salmonella immunized calves (Group III, immunized subcutaneously). Lanes 1-4, serum from calf 3033; lanes 5-8, calf 7643; lanes 9-12, calf 9263 . (C) As (B) using sera from recombinant Salmonella immunized calves (Group IV, immunized orally). Lanes 1-4, calf 7775; lanes 5-8, calf 1045; lanes 9-12, calf 4063 
Induction of protective immunity to Theileria annulata: C. d'Oliveira et al.
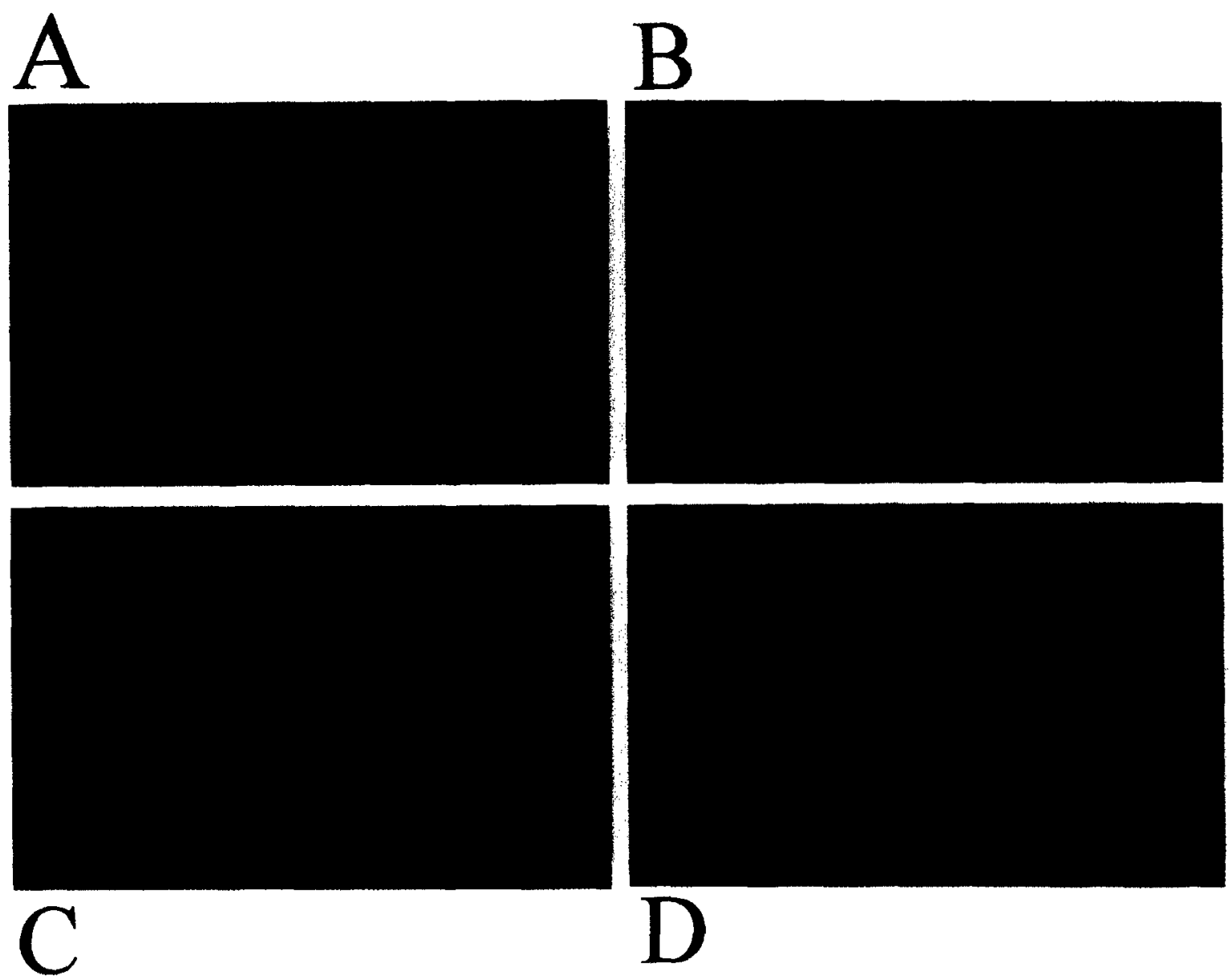

Figure 3 Immunofluorescence reactivity of antibodies generated at the time of challenge in ISCOM-immunized animals against acetonefixed slide preparations of $T$. annulata (Ankara) piroplasms $(\times 500$ ). (A) Control mAb 5E1; (B) calf 473; (C) calf 474; (D) calf 475

A

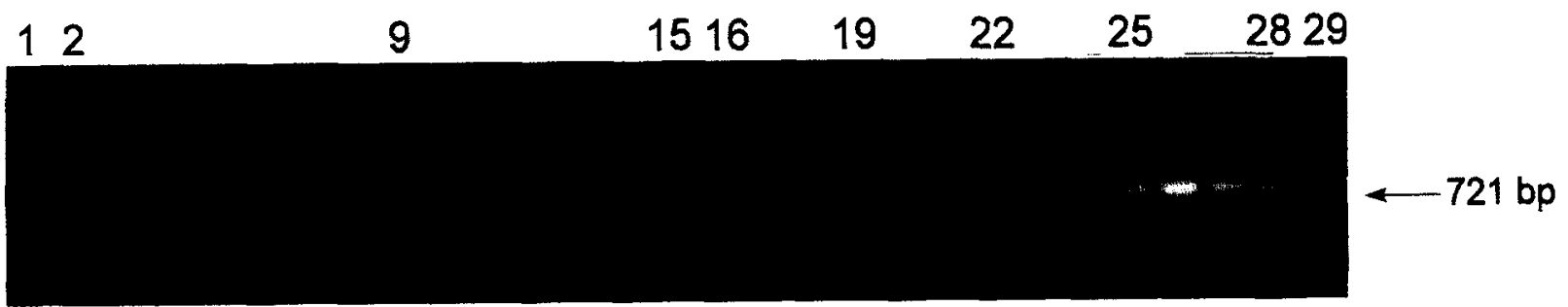

B
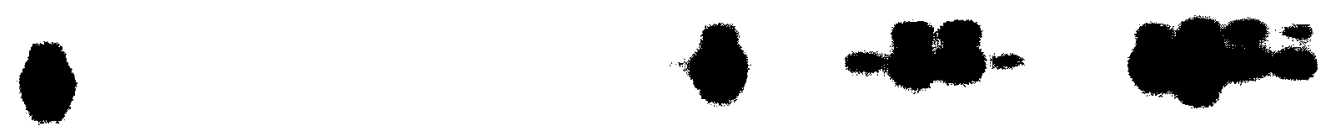

Figure 4 Agarose gel electrophoresis (A) and Southern blot hybridization using the c-DNA probe (B) of amplified DNA from calves immunized with iscoms (Group I) and control call \#476 (Group V) using primers 1 and 2. Lanes: 1, distilled water; 2, T.annulata positive control; 3 and 29, molecular size markers (pBluescript[Stratagene, La Jolla, CA, USA] digested with Hinfl); 4 to 9, calf \#473: 4, prior to challenge; 5 , week 2 post-challenge; 6 , week 3 post-challenge; 7 , week 4 post-challenge; 8 , week 8 post-challenge; 9 , week 12 postchallenge; 10 to 16 , calf \#474: same as above, except an additional lane 16, week 23 post-challenge; 17 to 22 , calf \#475: same as above; 23 to 28 , calf \#476: same as above. 
extent against re-Tams1-2 at the time of challenge [Figure 2(B), lanes 1, 2, 9 and 10]. Preimmune sera taken from the same animals did not react with either recombinant antigen or LPS (data not shown). As a control, anti-Salmonella LPS serum raised in rabbit reacted with Salmonella-LPS [Figure 1(B), lanes 3 and 4 ].

\section{DISCUSSION}

In the present paper we have shown the ability of re-(Tams1-1 and/or Tams1-2) to induce protective immunity in cattle against tropical theileriosis, using ISCOMs and naked DNA to deliver these antigens, whereas all three unimmunized control animals developed disease. Salmonella-based delivery did not induce any protection; in contrast, two of six animals died of tropical theileriosis.

\section{ISCOM immunized calves}

At the time of challenge, all three ISCOM immunized calves had generated antibodies which recognized the piroplasm by IFAT. The pattern of staining was identical to that detected by monoclonal $5 \mathrm{E} 1$, which has been shown to bind to the surface of the merozoite ${ }^{28}$, suggesting that antibody generated against the ISCOMs results against the merozoite surface. Therefore, protection may have been due to high amounts of circulating antibodies to re-(Tams1-1 and Tams1-2), which bind to the merozoite surface and prevent invasion of erythrocytes or opsonize the parasite for clearance in the spleen by macrophages. Serum from calf 475 showed a weak reaction in IFAT compared with the other two calves, which might be the reason why the animal developed a higher piroplasm parasitaemia (1\%). To investigate the possibility of a Th-cell mediated immunity, a lymphocytestimulation assay will be used in further studies to characterize the phenotype of Th cells elicited by inoculation of re-(Tams1-1 and/or Tams1-2).

Since ISCOMs were described by Morein et al." numerous studies have demonstrated their potential as a vaccine with built-in adjuvant properties. Bacterial, parasitic, viral and other proteins and peptides have been incorporated into ISCOMs to enhance the immune response in various ways, including activation of helper ${ }^{31}$ and cytotoxic ${ }^{31} \mathrm{~T}$ cells and generation of potent long-lasting antibody responses ${ }^{32}$. Protection against lethal Toxoplasma gondii ${ }^{33}$, Trypanosoma cruzi $^{34}$ and Eimeria falciformis ${ }^{35}$ infections has been induced in mice by immunization with ISCOMs containing one or several isolated parasite antigens.

\section{Naked DNA immunized calves}

Two of three naked DNA immunized calves were protected, although one had fever for 1 day accompanied by a maximum piroplasm parasitaemia of $1 \%$. There were no detectable antibodies generated against the recombinants, which suggests that protective immunity is dependent on T cells. Sedegah et al. ${ }^{36}$ have shown $68 \%$ protection in mice against Plasmodium yoelii infection using plasmid DNA encoding the $P$. yoelii circumsporozoite protein, and that protection was dependent on $\mathrm{CD}^{+} \mathrm{T}$ cells.
Intradermal instead of intramuscular administration may improve the results ${ }^{37}$. Skin-associated lymphoid tissues contain specialized cells that enhance immune responses, e.g. the dendritic cell and the macrophages of the dermis can also take up antigen and initiate immune responses. Therefore, the in vivo transfection of epidermal or dermal cells by DNA would be expected to provide a more efficient route for DNA immunization. A further improvement may be gene gun-based DNA immunization using a hand-held gene delivery instrument that requires $>5000$-fold less DNA to induce similar responses via intramuscular or intradermal inoculation ${ }^{37}$.

\section{Recombinant Salmonella immunized calves}

None of the recombinant Salmonella immunized calves were protected, and two of the six animals died of tropical theileriosis. Only calves 3033 and 9263 had generated antibodies against re-(Tams1-1 or Tams1-2) at a relatively low level at the time of challenge and, in contrast to the ISCOM antisera, these were biased towards the re-Tams1-1 protein. Moreover, calf 9263 died of tropical theileriosis. This observation suggests that the recombinants were not produced at sufficient levels or in the appropriate form to induce adequate humoral and/or cell-mediated responses, possibly due to plasmid instability or toxicity of the recombinants in vivo. We recently reported that pSTams1-1 or pSTams1-2 and pIP5 can be maintained for at least $48 \mathrm{~h}$ in $S$. typhimurium SL3261 in vitro ${ }^{14}$. Stabilization of antigen production could be further attained by insertion of the gene into the bacterial chromosome ${ }^{3 s}$. Also, Sadoff $e t$ al $^{39}$ have shown that the gene encoding the circumsporozoite (CS) antigen of $P$. berghei when expressed in $S$. typhimurium can induce an antigenspecific cell-mediated immune response in mice and provided protection against sporozoite challenge in the absence of measurable antibody to CS protein.

\section{Control calves}

Group V animals received infected blood only and exhibited a very quick increase in piroplasm parasitaemia (from 5 to $20 \%$ in $24 \mathrm{~h}$ ). Furthermore, on Giemsa-stained blood smears no Maltese crosses were detected which are typical for division of piroplasms within erythrocytes. Instead, multiple piroplasm infections were seen within individual erythrocytes, indicating the presence of macroschizont-infected leucocytes in the blood stabilate which differentiate to produce merozoites. This could be directly from infected cells within the stabilate or, more probably, following transfer of the schizont to the host cell of the immunized animal. Indeed, macroschizont-infected leucocytes could be detected in the spleen and liver of both animals that died. As it is known that Tams1-1 is produced by macroschizonts ${ }^{23}$ (at a low level) before differentiation to merozoites occurs, it is conceivable that peptides from these molecules are presented on the infected leucocyte together with MHC-I and recognized by cytotoxic T cells. Alternatively, the production of INF- $\gamma$ by Th1 cells may activate macrophages and prevent the establishment of the macroschizont within leucocytes, as previously shown in vitro by Preston et $a l^{40}$ and Visser $e t a l{ }^{41}$. As we did not obtain data on the $\mathrm{T}$ cell response in immunized animals, the 
mechanism by which protection occurs is unclear at the present time. Further immunization trials are being conducted using ISCOMs with re-(Tams1-1 and Tams1-2) proteins combined with re-SPAG, and naked DNA encoding these proteins. Ultimately, it is likely that a subunit recombinant vaccine consisting of engineered antigens from sporozoites, schizonts as well as from merozoites/piroplasms will be necessary to induce protection against $T$. annulata infection, initiated through the bite of an infected tick.

\section{ACKNOWLEDGEMENTS}

We thank Professor C.G.D. Brown (CTVM, Edinburgh, UK) for T. annulata ground-up tick supernate, Professor L. Babiuk and Dr J. Lewis (University of Saskatchewan, Saskatoon, Canada) for pSLRSV.Nul plasmid and helpful discussions, Dr J.G. Kusters (Free University, Amsterdam, Netherlands) for ATCC 14028 and Dr E.J. Tijhaar (University of St. Andrews, UK) for rabbit anti-S. typhimurium LPS. Professor A. Tait (University of Glasgow, UK) and Drs R. Hall, N. Boulter (University of York, UK), H. Schallig and C. Broeren (Utrecht University) are thanked for critical reading of the manuscript. This work was supported by the European Union (Directorate General XII) under contract TS3*-CT91-0019, entitled 'The Characterization of Protective Antigens and Their Genes from Theileria annulata'.

\section{REFERENCES}

1 Uilenberg, G. Theilerial species of domestic livestock. In Advances in the Control of Theileriosis (Eds Irvin, A.D., Cunningham, M.P. and Young, A.S.). Martinus Nijhoff, The Hague, 1981, pp. 4-37.

2 Robinson, P.M. Theileria annulata and its transmission-a review. Tropical Animal Health and Production 1982, 14, 3-12.

3 Glass, E.J., Innes, E.A., Spooner, R.L. and Brown, C.G.D. Infection of bovine monocyte/macrophage populations with Theileria anmulata and Theileria panva. Veterinary Immunology and Immunopathology 1989, 22, 355-368.

4 Spooner, R.L., Innes, E.A., Glass, E.J. and Brown, C.G.D. Theileria annulata and Theileria parva infect and transform different bovine mononuclear cells. Immunology 1989, 66, 284-288.

5 Hashemi-Fesharki, R. Control of Theileria annulata in Iran. Parasitology Today 1988, 4, 36-40.

6 Pipano, E. Bovine theileriosis in Israel. Rev. Sci. Tech. Off. Int Epiz. 1989, 8, 79-87.

7 Stepanova, N.I. and Zablotskii, V.T. Bovine theileriosis in the USSR. Rev. Sci. Tech. Off. Int. Epiz. 1989, 8, 89-92.

8 Grewal, A.S., Singh, A., Kondal, J.K. and Kapur, J. Theileria annulata vaccination field trials at village level in young crossbred calves in the Punjab State, India (1991-1993). In European Union Third Coordination Meeting on Tropical Theileriosis (Eds Spooner, R.L. and Campbell, J.D.). The Roslin Institute, Roslin, UK, 1994, pp. 30-36.

9 Sabanshiev, M. Theileriosis of cattle in Kazakhstan. In European Union Third Coordination Meeting on Tropical Theileriosis (Eds Spooner, R.L. and Campbell, J.D.). The Roslin Institute, Roslin, UK, 1994, pp. 10-12.

10 Wenshun, L. and Hong, Y. Bovine and ovine theileriosis in China and its immune prophylaxis. In European Union Third Coordination Meeting on Tropical Theileriosis (Eds Spooner. R.L. and Campbell, J.D.). The Roslin Institute, Roslin, UK, 1994 , pp. 13-17
11 Pipano, E. Schizonts and tick stages in immunization against Theileria annulata infection. In Advances in the Control of Theileriosis (Eds Irvin, A.D., Cunningham, M.P. and Young. A.S.). Martinus Nijhoff, The Hague, 1981, pp. 242-252.

12 Williamson, S., Tait, A., Brown, D., Walker, A., Beck, P., Shiels, B., Fletcher, J. and Hall, R. Theileria annulata sporozoite surface antigen expressed in Escherichia coli elicits neutralizing antibody. Proceedings of the National Academy of Sclences of the United States of America 1989, 86, 4639-4643.

13 Boulter, N.R., Glass, E.J., Knight, P.A., Bell-Sakyi, L., Brown, C.G.D. and Hall, R. Theileria annulata sporozoite antigen fused to hepatitus $B$ core antigen used in a vaccination trial. Vaccine 1995, 13, 1152-1160.

14 d'Oliveira, C., Tijhaar, E., Shiels, B.R., van der Weide, M. and Jongejan, $F$. Expression of genes encoding two major Theileria annulata merozoite surface antigens in Escherichia coli and a Salmonella typhimurium aroA vaccine strain. Gene 1996, 172, 33-39.

15 Villarejo, M.R. and Zabin, I. Beta-galactosidase from termination and deletion mutant strains. Journal of Bacteriology 1974, 120, 466-474

16 Hoiseth, S.K. and Stocker, B.A.D. Aromatic-dependent Salmonella typhimurium are non-virulent and effective as live vaccines. Nature 1981, 291, 238-239.

17 Sambrook, J., Fritsch, E.F. and Maniatis, T. In Molecular Cloning, A Laboratory Manual. Cold Spring Harbor Laboratory Press, Cold Spring Harbor, NY, 1989.

18 Hitchcock, P.J. and Brown, T.M. Morphological heterogeneity among Salmonella lipopolysaccharide chemotypes in silverstained polyacrylamide gels. Journal of Bacteriology 1983 . 154, 269-277.

19 Fitzpatrick, D.R., Zamb, T., Parker, M.D., Van Drunen Littel van den Hurk, S., Babiuk, L.A. and Lawman, M.J.P. Expression of bovine herpesvirus 1 glycoproteins $\mathrm{gl}$ and glll in transfected murine cells. Journal of Virology 1988, 62, 4239-4248.

20 Tikoo, S.K., Fitzpatrick, D.R., Babiuk, L.A. and Zamb, T.J. Molecular cloning, sequencing, and expression of functional bovine herpesvirus 1 glycoprotein gIV in transfected bovine cells. Journal of Virology 1990, 64, 5132-5142.

21 Cox, G.J.M., Zamb, T.J. and Babiuk, L.A. Bovine herpesvirus 1: immune responses in mice and cattle injected with plasmid DNA. Journal of Virology 1993, 67, 5664-5667.

22 Sanger, F., Nicklen, S. and Coulson, A.R. DNA sequencing with chain terminating inhibitors. Proceedings of the National Academy of Sciences of the United States of America 1977, 74, 5463-5467.

23 Shiels, B.R., Smyth, A., Dickson, J., McKellar, S., Tetley, L., Fujisaki, K., Hutchinson, B. and Kinnaird, J.H. A stoichiometric model of stage differentiation in the protozoan parasite Theileria annulata. Molecular and Cellular Differentiation 1994. 2, 101-125.

24 d'Oliveira, C., van der Weide, M., Habela, M.A., Jacquiet, P. and Jongejan, F. Detection of Theileria annulata in blood samples of carrier cattle by PCR. Journal of Clinical Microbiology 1995, 33, 2665-2669.

25 Schein, E., Buscher, G. and Friedhoff, K.T. Lichtmikroskopie Untersuchungen über die Entwicklung von Theileria annulata in Hyalomma anatolicum. Zoitschrift fur Parasitenkunde 1975 , 48, $123-126$.

26 Minami, T., Spooner, R.L., Irvin, A.D., Ocama, J.G.R., Dobbelaere, D.A.E. and Fujinaga, T. Characterisation of stocks of Theileria parva by monoclonal antibody profiles. Research in Veterinary Science 1983, 35, 334-340.

27 Shiels, B., McDougall, C., Tait, A. and Brown, C.G.D. Antigenic diversity of Theileria annulata macroschizonts. Veterinary Parasitology 1986, 21, 1-10.

28 Glascodine, J., Tetley, L., Tait, A., Brown, D. and Shiels, B. Developmental expression of a Theileria annulata merozoite surface antigen. Molecular and Biochemical Parasitology 1990, 40, 105-112.

29 Morein, B., Sundquist, B., Hoglund, S., Dalsgaard, K and Osterhaus, A. Iscom, a novel structure for antigenic presentation of membrane proteins from enveloped viruses. Nature 1984, 308, 457-460.

30 Villacres-Eriksson, M., Bergstrom-Mollauglu, M., Kaberg, $H$. and Morein, B. Involvement of interleukin-2 and interferon- 
gamma in the immune response induced by influenza virus iscoms. Scandinavian Journal of Immunology 1992, 36, 421-426.

31 Takahashi, H., Takeshita, T., Morein, B., Putney, S., Germain, R.N. and Berzofsky, J. Induction of CD8 + cytotoxic T cells by immunization with purified HIV-1 envelope proteins in iscoms Nature 1990, 344, 873-875.

32 Claassen, I. and Osterhaus, A. The iscom structure as an enhanced moiety: experiences in viral systems. Research in Immunology 1992, 143, 531-541.

33 Lunden, A., Lovgren, K., Uggla, A. and Araujo, F.G. Immune responses and resistance to Toxoplasma gondii in mice immunized with antigens of the parasite incorporated into immunostimulating complexes. Infection and Immunity 1993. 61, 2639-2643.

34 Araujo, F.G. and Morein, B. Immunization with Trypanosoma cruzi epimastigote antigens incorporated into iscoms protects against lethal challenge in mice. Infection and Immunity 1991 , 59, 2909-2914.

35 Kazanji, M., Laurent, F. and Pery, P. Immune responses and protective effect in mice vaccinated orally with surface sporozoite protein of Eimeria falciformis in iscoms. Vaccine 1994, 12, 798-804.

36 Sedegah, M., Hedstrom, R., Hobart, P. and Hoffman, S.L. Protection against malaria by immunization with plasmid DNA encoding circumsporozoite protein. Proceedings of the
National Academy of Sciences of the United States of America 1994, 91, 9866-9870.

37 Pertmer, T.M., Eisenbraun, M.D., McCabe, D., Prayaga, S.K., Fuller, D.H. and Haynes, J.R. Gene gun-based nucleic acid immunization: elicitation of humoral and cytotoxic T lymphocyte responses following epidermal delivery of nanogram quantities of DNA. Vaccine 1995, 13, 1427-1430.

38 Strugnell, R., Maskell, D., Fairweather, N., Pickard, D., Cockayne, A., Penn, C. and Dougan, G. Stable expression of foreign antigens from the chromosome of Salmonella typhimurium vaccine strains. Gene $1990,88,57-63$.

39 Saddoff, J.C., Ballou, W.R., Baron, L.S., Majarian, W.R., Brey, R.N., Hock meyer, W.T., Young, J.F., Cryz, S.J., Ou, J., Lowell, G.H. and Chulay, J.D. Oral Salmonella typhimurium vaccine expressing circumsporozoite protein protects against malaria. Science 1988, 240, 336-338.

40 Preston, P.M., Brown, C.G.D. and Richardson, W. Cytokines inhibit the development of trophozoite-infected cells of Theileria annulata and Theielria parva but enhance the proliferation of macroschizont-infected cell lines. Parasite Immunology 1992, 14, 125-141.

41 Visser, A.E., Abraham, A., Bell-Sakyi, L.J., Brown, C.G.D. and Preston, P.M. Nitric oxide inhibits establishment of macroschizont-infected cell lines and is produced by macrophages of calves undergoing bovine tropical theileriosis or East Coast fever. Parasite Immunology 1995, 17, 91-102. 